\title{
Leiomyoma of the iris
}

\section{Report of a case}

\author{
S. de BUEN*, M. L. OLIVARES†, AND G. GHARLIN V. \\ From Mexico City* and † $\ddagger$ Santiago, Chile
}

Leiomyomata of the iris are infrequent (Erdbrink and Harbert, I955), and represent, according to the literature, between $2 \cdot 3$ and 14 per cent. of all iris tumours. They have been reported only in white subjects aged between 10 and 77 years, females being more frequently affected. They involve most commonly the lower half of the iris, more often on the temporal side, and may arise from either the sphincter or the dilator muscle. Despite the neuroectodermal origin of the iris muscles, the tumour is a typical leiomyoma, showing histological features similar to those originating in the mesodermal smooth muscles. They appear as a well circumscribed, slightly elevated, greyish-white or pink, vascularized mass, hyphaema being not unusual. The pupillary reflexes are not usually affected and ectropion uveae is frequent. Clinical symptoms are absent (Ferrer, 1949) and vision is not impaired unless hyphaema, cataract, or secondary glaucoma develops.

The clinical diagnosis is difficult because in a high percentage of cases it is impossible to differentiate an iris leiomyoma from a lightly-pigmented malignant melanoma (DukeElder, I966).

The treatment of choice is total excision of the tumour when it is well limited, but if the growth is active, with diffuse invasion of the iris and/or extension to the anterior chamber angle, the eye should be enucleated.

Prognosis is good if the tumour is removed before invasion of the neighbouring structures has occurred. No metastases have been reported but there may be local recurrence when the tumour is not totally excised.

Histologically (Brown, Kellenberger, Hudson, and Matthews, I957; Nordmann and Brini, I962; Ashton and Wybar, I966; Cullmann, I968), iris leiomyomata show elongated interlacing spindle cells, with oval, sometimes palisaded nuclei, and eosinophilic cytoplasm containing numerous myoglial fibrils best demonstrated with Mallory phosphotungstic-acid haematoxylin, Masson's trichrome stain, and gold impregnation.

\section{Case report}

A 68-year-old white male showed a discoloured slightly raised tumour mass in the iris of the right eye of several months' duration, with moderate pupillary deformity and slight ectropion uveae; 6 weeks later the iris mass was found to be larger and there was more marked ectropion and pupillary traction. Slit-lamp examination revealed pigment dust on the posterior surface of the cornea. The anterior chamber showed normal depth, the angle was open, and there was an aqueous flare.

\footnotetext{
Presented by C.C.V. at the 7th Meeting of the Southern Ophthalmic Pathology Society, in Lima, Peru, January 8-1 r, I969. *Laboratory of Ophthalmic Pathology, Department of Ophthalmology, General Hospital, S.S.A., Mexico City, Mexico. †Department of Ophthalmology, Hospital José Aguirre, Santiago, Chile. ‡Department of Ophthalmology, Hospital del Salvador, Santiago, Chile.
} 
There was a pinkish-yellow, poorly circumscribed elevated mass on the lower temporal quadrant of the iris, between the pupillary margin and the collarette projecting into the anterior chamber (Fig. 1). Schiötz tension was normal in both eyes. The corrected visual acuity was $5 / 7 \cdot 50$ in the right eye and $5 / 5$ in the left.

The diagnoses of leiomyosarcoma or melanoma of the iris were considered and a wide excision of the tumour was performed on February 5, 1968, under general anaesthesia (Figs 2 and 3).

\section{(1)}

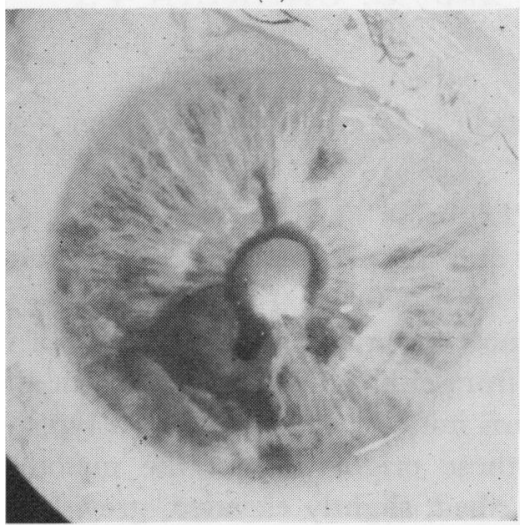

(3)

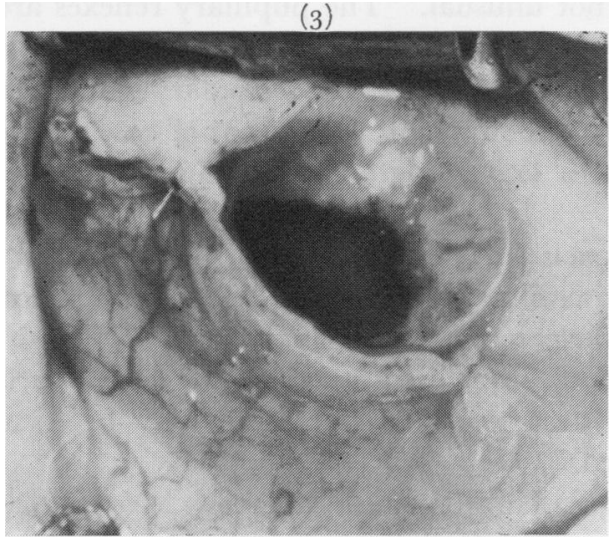

(2)

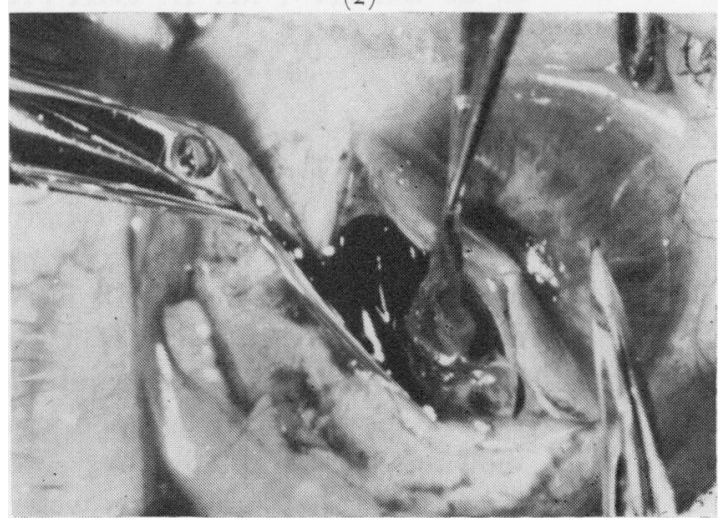

FIG. I Slightly elevated tumour mass in lower temporal quadrant of right iris

FIG. 2 Surgical excision of neoplasm

FIG. 3 Postoperative photograph, showing wide iridectomy and total removal of neoplasm

\section{PATHOLOGICAL FINDINGS}

Macroscopically the formalin-fixed specimen consists of a triangular-shaped flat fragment of darkgreyish tissue, measuring $7 \times 4.5 \times 2 \mathrm{~mm}$., with a central lobulated whitish firm excrescence, measuring $4+3+2 \mathrm{~mm}$. (Fig. 4, opposite).

Microscopically, arising from the dilator muscle and spreading through the iris stroma to reach the anterior surface of the iris (Fig. 5), there is a neoplasm composed of interlacing bundles of spindle cells with elongated basophilic nuclei with blunted ends and fibrillar acidophilic cytoplasm. No mitoses are seen. A wide area of tumour-free iris tissue is present on both sides of the neoplasm. Special stains (Masson's and Gomori's trichrome) revealed longitudinal fibrils within the cytoplasm of the tumour cells (Fig. 6, overleaf). On cross-section the cytoplasm is seen to be granular (Fig. 7, overleaf).

\section{Diagnosis}

Leiomyoma of the iris, arising in the dilator muscle. 


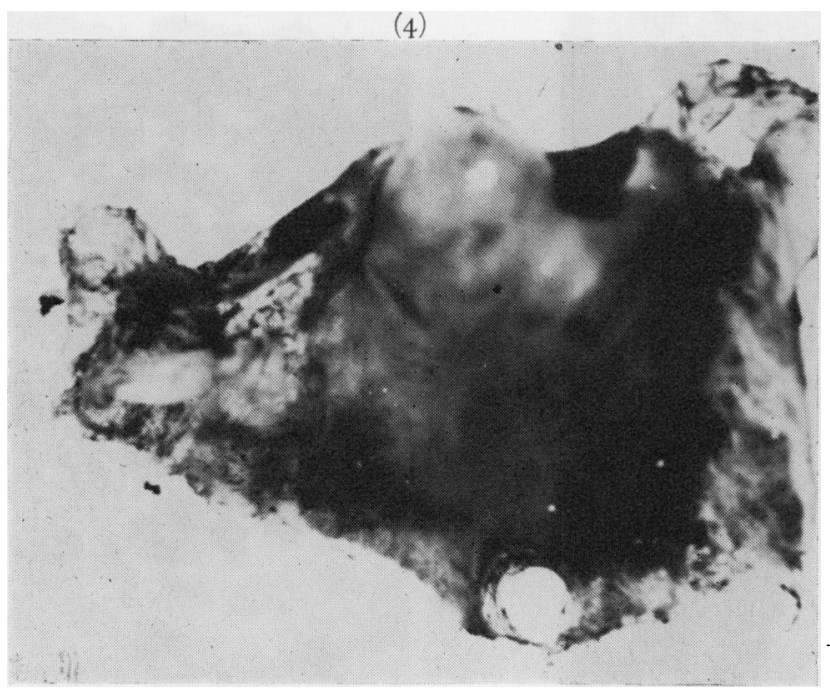

FI G. 4 Surgical specimen, showing tumour mass protruding centrally

FIG. 5 Tumour cells arising from dilator muscle and spreading through stroma to reach anterior surface of iris. Haematoxylin and eosin. $\times 80$

(5)

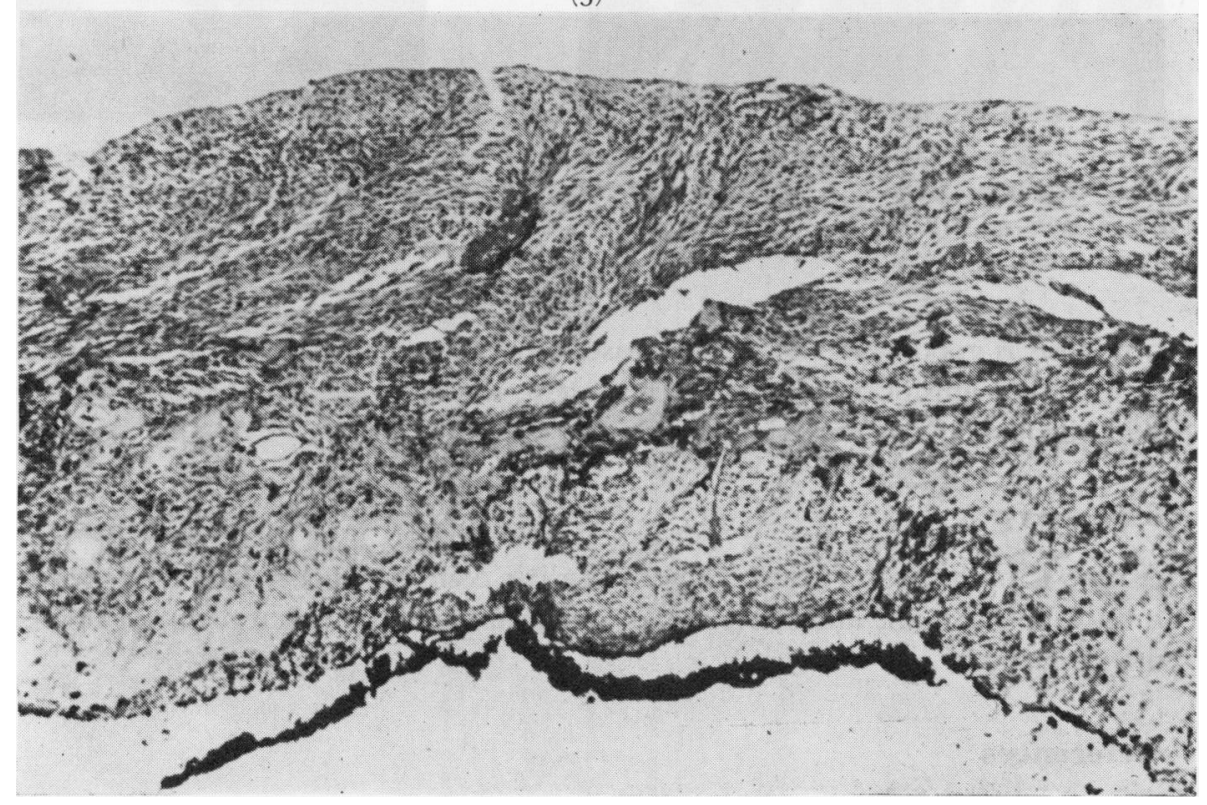

\section{Comment}

This iris leiomyoma is typical both clinically and pathologically. Its location in the lower temporal quadrant is the most common as recorded in the literature.

The eye was treated surgically by performing a wide iridectomy to obtain a total excision of the tumour. This is the same treatment as is recommended in other well localized iris tumours, including malignant melanomata, for which reason the clinical difficulty of establishing a precise differential diagnosis is of limited importance. Only a careful histological study, using special stains to demonstrate the intracytoplasmic longitudinal fibrils, will permit the correct diagnosis. When the tumour is removed in toto the 


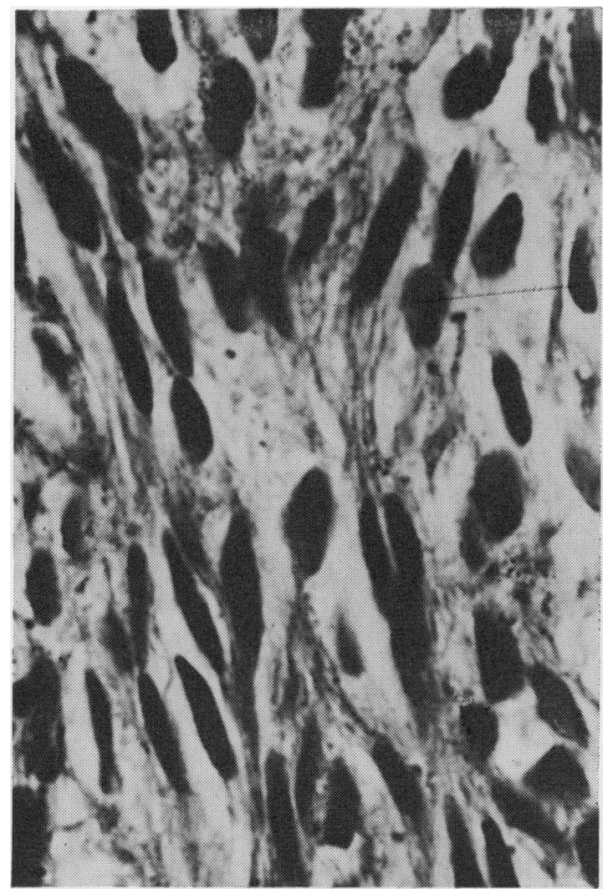

F I G. 6 Elongated tumour cells with longitudinal fibrils within cytoplasm. Note that most of the nuclei show blunted ends. Masson's trichrome. $\times 920$ (oil immersion)

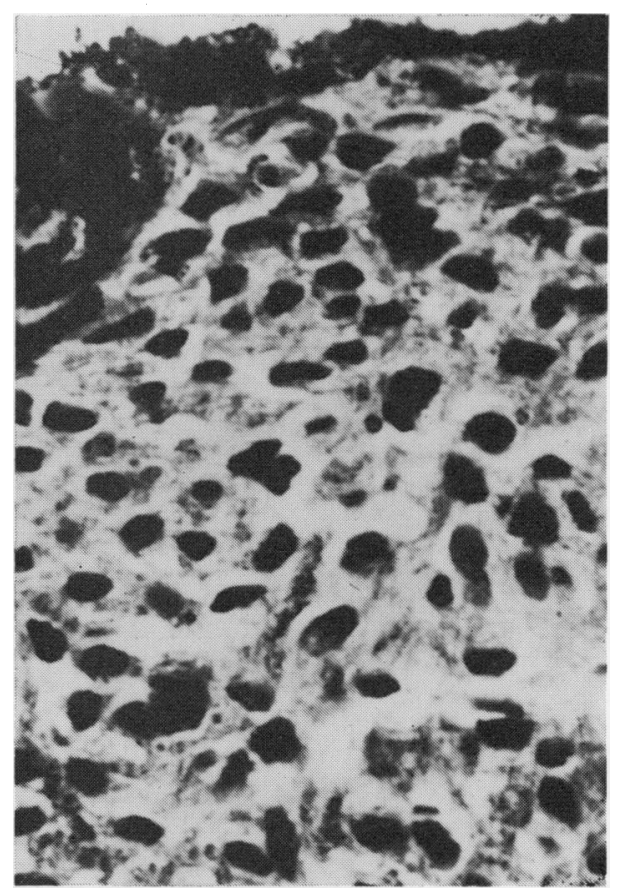

FIG. 7 Cross-section of tumour cells, showing granular cytoplasm. Masson's trichrome. $\times 920$ (oil immersion)

prognosis is good. In the present case, on August 5, 1970, that is $2 \frac{1}{2}$ years after the iridectomy, no signs of recurrence were present, the anterior chamber was deep and there was no aqueous flare or posterior synechiae.

\section{Summary}

A case is presented of leiomyoma of the iris confined to the lower temporal quadrant in a 68-year-old man, and the clinical and histological characteristics of this rare neoplasm are described.

\section{References}

ASHTON, N., and WYBAR, K. (1966) Ophthalmologica (Basel), I5I, 97

BRown, w. C., Kellenberger, R. E., hidson, K. E., and matthews, J. L. (1957) Amer. J. Ophthal.,

43, 457

Gullmann, B. (1968) v. Graefes Arch. Ophthal., 175, 208

DUKE-ELDER, S. (1966) “System of Ophthalmology", vol. 9, "Diseases of the Uveal Tract," p. 8o3.

Kimpton, London

ERDBRINK, W. L., and HARBERT, F. (1955) A.M.A. Arch. Ophthal., 53, 643

FERRER, O. (1949) Arch. Soc. Estud. clin. Habana, 42, I

NORDMANN, J., and BRINI, A. (1962) Bull. Soc. Ophtal. Fr., p. 108 